\title{
Optical Dynamics at the Au/ZnPc Interfaces
}

\author{
A. F. Qasrawi ${ }^{a, b, *}$ (D), Hadeel M. Zyoud ${ }^{a}$ \\ ${ }^{a}$ Arab American University, Department of Physics, Jenin, Palestine \\ ${ }^{b}$ Atilim University, Faculty of Engineering, Group of physics, 06836 Ankara, Turkey
}

Received: February 17, 2020; Revised: May 4, 2020; Accepted: May 27, 2020

\begin{abstract}
In this work, the optical dynamics and the structural properties of the zinc phthalocyanine which are coated onto $150 \mathrm{~nm}$ thick Au substrates are studied by the X-ray diffraction and optical spectrophotometry techniques. The $\mathrm{Au} / \mathrm{ZnPc}$ interfaces appears to be strongly affected by the large lattice mismatches at the interface. It is observed that the coating $\mathrm{ZnPc}$ onto Au substrates increases the light absorbability by 4.7 and 128.2 times in the visible and infrared regions of light, respectively. $\mathrm{Au}$ substrates activated the free carrier absorption mechanism in the $\mathrm{ZnPc}$ thin films in the infrared range of light. In addition, the transparent Au substrates forced narrowing the energy band gap in both of the $\mathrm{Q}$ and $\mathrm{B}$ bands. It also increased the dielectric constant value by $\sim 3.5$ times in the IR range. The enhancements in the optical properties of $\mathrm{ZnPc}$ that resulted from the thin Au substrates make the $\mathrm{ZnPc}$ more suitable for optoelectronic, nonlinear optical applications and for electromagnetic energy storage in the infrared range of light.
\end{abstract}

Keyword: Au/ZnPc; X-ray diffraction; optical absorption; band gap; dielectric dispersion.

\section{Introduction}

Zinc phthalocyanine $(\mathrm{ZnPc})$ is a compound that exhibits smart features nominating it for many applications. The kind of application of this material depends on the substrates they grow onto. As for examples, $\mathrm{ZnPc}$ thin films which are coated onto $\mathrm{Fe}_{2} \mathrm{O}_{3}$ are reported to be beneficial or photodynamic therapy and for magnetic resonance imaging ${ }^{1}$. $\mathrm{ZnPc} /$ carbon nitride interfaces are observed to display high efficiency in photoelectrocalytic reduction of $\mathrm{CO}_{2}$ under visible light ${ }^{2}$. In addition, heterojunctions composed of $\mathrm{C}_{60}$ and zinc phthalocyanine which are used to fabricate organic photodiodes exhibited a photoresponsivity of $5.21 \mathrm{~A} / \mathrm{W}$ when irradiated with light of intensity of $68 \mu \mathrm{W} / \mathrm{cm}^{23}$. Moreover, as a nonlinear optical media, when tested with the Z-scan technique using $532 \mathrm{~nm}$ pulsed lasers, the metal phthalocyanine/graphene oxide (GO) interfaces displayed third order nonlinear optical absorption ${ }^{4}$. Furthermore, when the $\mathrm{CdS} / \mathrm{CdSe}$ solar cells were coated with $\mathrm{ZnPc}$ the short current density, open circuit voltage and photocell efficiency increased to $11.3 \mathrm{~mA} / \mathrm{cm}^{2}, 0.66 \mathrm{~V}$ and $4.01 \%$, respectively ${ }^{5}$.

Literature data mentioned the novelty of $\mathrm{ZnPc}$ for use in the technology of nanogenerator ${ }^{6,7}$ which are well known for their high energy conversion efficiency ${ }^{7}$. Recently, Zinc phthalocyanine nanorods which are grown onto flexible aluminum foil (Al) are nominated for use in the nanogenerators technology. Al play the role of substrate to grow nanorods and as bottom electrodes. For such system an open circuit voltage of $0.524 \mathrm{mV}$ for $\mathrm{ZnPc}$ rods of lengths of $100 \mathrm{~nm}$ is achieved. This open circuit voltage reaches $0.968 \mathrm{mV}$ when the length of the rod is increased to $300 \mathrm{~nm}^{6}$.

The wide range of applications and the effect of the type of substrate on the performance of $\mathrm{ZnPc}$ thin films,

*e-mail: atef.qasrawi@atilim.edu.tr; atef.qasrawi@aaup.edu which are additionally summarized in Table 1, motivated us to study the relation between transparent Au layers and $\mathrm{ZnPc}$ thin films. This type of interfaces may open the doors for new class of applications that need electrical contacts and high optical transparency to carryout dual operations. For this reason, here in this work, we will investigate the structural and optical properties of $\mathrm{ZnPc}$ films which are coated onto glass substrates and compare them with those coated onto $150 \mathrm{~nm}$ thick Au substrates. The feature of the transparent $\mathrm{Au}$ substrate lay in its high conductivity and high light transparency. The effect of $\mathrm{Au}$ on the crystal structure, optical absorption, light absorbability, energy band gap and dielectric constant will be reported and discussed. Enhancement of these physical parameters will make the $\mathrm{ZnPc}$ more attractive for use in optoelectronics as multifunctional devices.

\section{Experimental details}

Both of the $\mathrm{Au}$ and $\mathrm{ZnPc}$ thin films are coated onto ultrasonically cleaned glass substrates with the help of VCM-600 thermal evaporator under vacuum pressure of $10^{-5} \mathrm{mbar}$. The deposition parameters during the evaporation cycle are listed in Table 2 . The respective thicknesses of the films were 150 and $600 \mathrm{~nm}$. The evaporation sources were $\mathrm{Au}$ wires and $\mathrm{ZnPc}$ nano-powders. The Au substrates were also employed to grow the $600 \mathrm{~nm}$ thick layers of $\mathrm{ZnPc}$. The thicknesses of the films were measured with Inficon STM-2 thickness monitor which have resolution of $0.037 \AA$. The measurement intervals of the monitor are $0.1 \mathrm{~s}$ spaced. The monitor detecting face was set parallel to the glass substrates so that it read the same thicknesses of the grown films. As confirmative procedure, the produced 
Table 1: Optoelectronic devices comprising $\mathrm{ZnPc}$ in its structure.

\begin{tabular}{llc}
\hline \multicolumn{1}{c}{ Device structure } & \multicolumn{1}{c}{ Class of applications } & Reference \\
\hline $\mathrm{Fe}_{2} \mathrm{O}_{3} / \mathrm{ZnPc}$ & Photodynamic therapy and for magnetic resonance imaging & Qin et al. $^{1}$ \\
\hline $\mathrm{ZnPc} / \mathrm{C}_{3} \mathrm{~N}_{4}$ & Photoelectrocalytic reduction of $\mathrm{CO}_{2}$ & Zheng et al. $^{2}$ \\
\hline $\mathrm{C}_{60} / \mathrm{ZnPc}$ & Organic photodiodes with high responsivity & Ding et al. $^{3}$ \\
\hline $\mathrm{ZnPc} / \mathrm{C}_{140} \mathrm{H}_{42} \mathrm{O}_{20}{ }^{*}$ & Third order nonlinear optical absorption & $\mathrm{Zu} \mathrm{et} \mathrm{al.}^{4}$ \\
\hline $\mathrm{CdS} / \mathrm{CdSe} / \mathrm{ZnPC}$ & Solar Cells & Chen et al. $^{5}$ \\
\hline $\mathrm{Al} / \mathrm{ZnPc}$ & Nanogenerators & Godfrey et al. $^{6}$ \\
\hline
\end{tabular}

*Famous name: Graphene oxide

Table 2: The depostion parameters for $\mathrm{ZnPc}$ films.

\begin{tabular}{lc}
\hline \multicolumn{1}{c}{ Parameter } & Value \\
\hline Pre-deposition vacuum pressure $($ mbar $)$ & $4 \times 10^{-5}$ \\
\hline Evaporation Boat type & Tungsten $(0.1 \mathrm{~mm}$ thick $)$ \\
\hline Weight of ZnPC powder $(\mathrm{gr})$ & 0.14 \\
\hline Target to substrate distance $(\mathrm{cm})$ & 10 \\
\hline Temperature of substrate holder $\left({ }^{\circ} \mathrm{C}\right)$ & 25 \\
\hline Evaporation time $(\mathrm{min})$. & 13 \\
\hline Evaporation rate $(A / s)$ & 8.4 \\
\hline
\end{tabular}

films were measured with the help of surface roughness tester-profilometer (Model TR-200 plus). The profilometer reads $655 \mathrm{~nm}$ for the $\mathrm{ZnPc}$ films which differ by $9.1 \%$ from the monitor. The arithmetic average roughness $\left(R_{a}\right)$ was found to be $55 \mathrm{~nm}$. The thickness of the Au layer being $150 \mathrm{~nm}$ was optimized through successive cycles of evaporations to determine the best position of the glass substrates above the evaporation source and then confirming the thicknesses by the profilometer which is capable of recording thicknesses down to $5.0 \mathrm{~nm}$. The grown thin films of $\mathrm{Au} / \mathrm{ZnPc}$ are structurally and optically characterized using MiniFlex-600 X-ray diffraction unit with scanning speed of $0.5 \% \mathrm{~min}$ and Thermoscientific Evolution 300 spectrophotometer equipped with VEE MAX II reflectometer. The optical measurements were carried out in the spectral range of (300-1100 nm).

It is worth mentioning that the thickness of the samples being $600 \mathrm{~nm}$ is selected for the preparation of the $\mathrm{Au} / \mathrm{ZnPc}$ interfaces after various trails to optimize stable crystalline structure. Films of thicknesses in the range of 50-500 nm did not display any experimental intensive peaks in the XRD patterns. While, on the other hand, films of thicknesses of 600-1000 nm exhibited polycrystalline phase. Thus, the minimum thickness that reveal crystalline phase and highest transmittance of the crystalline phase was at $600 \mathrm{~nm}$.

\section{Results and Discussion}

The X-ray diffraction (XRD) patterns for zinc phthalocyanine thin films which are coated onto glass and transparent $\mathrm{Au}$ thin film substrates are shown in Figure 1. As mentioned, the transparent $\mathrm{Au}$ substrate thickness $(d)$ was $150 \mathrm{~nm}$. It is clear from the figure that the replacement of glass by $\mathrm{Au}$ has significant effect on the intensity and diffraction angle $(2 \theta)$ of the maximum peak. Particularly, as appears in inset-1 of Figure 1, the peak which was observed at $2 \theta=7.32^{\circ}$ and exhibit intensity $2.66 \times 10^{3}$ a.u shift to $2 \theta=7.25^{\circ}$

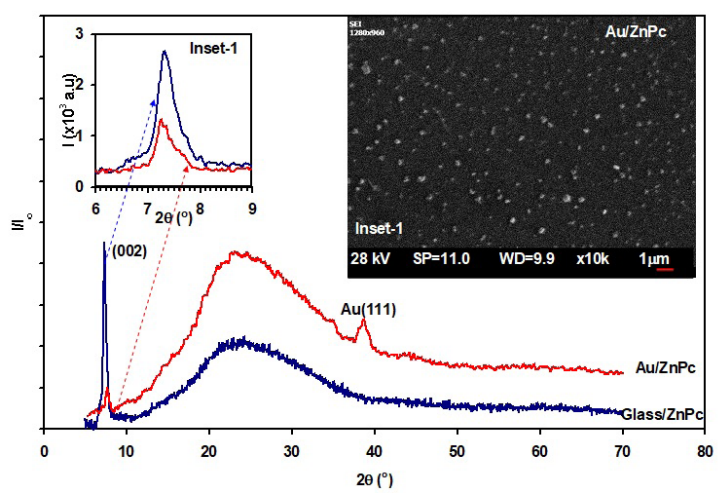

Figure 1. The X-ray diffraction patterns for $\mathrm{ZnPc}$ thin films which are coated onto glass and transparent Au substrates. Inset-1 represent an enlargement of the maximum peaks and inset-2 shows the scanning electron microscopy images for the $\mathrm{ZnPc}$ samples grown on Au substrates.

and display intensity value of $1.34 \times 10^{3} \mathrm{a}$.u. The maximum peak of the XRD patterns which is usually assigned to the monoclinic phase of $\mathrm{ZnPc}$ with unit cell parameters of $a=26.333 \AA, b=3.8133 \AA, c=23.7118 \AA$, and $\beta=94.2845^{\circ}$ and space group: $C_{2 / n}$ are oriented along the (002) direction ${ }^{8}$ (JCPDS card number 21-1985). As also observable from the XRD patterns of the $\mathrm{Au} / \mathrm{ZnPc}$ films, additional peak that is assignable to the face centered cubic gold with plane orientation along the (111) direction is presented. The calculated lattice parameter of gold is 4.05 $\AA$ (JCPDS Card No. 04-0784). As both of the $\mathrm{ZnPC}$ peaks exhibit the same broadening value $\left(\beta=0.375^{\circ}\right)$ no effect of Au substrates on the crystallite size or microstrain is expected. However, the large differences between the lattice parameters of the monoclinic unit cells of $\mathrm{ZnPc}$ and cubic $\mathrm{Au}$ turn the attention to the large lattice mismatch between the $\mathrm{Au}$ and $\mathrm{ZnPc}$ layers. Large lattice mismatch is mentioned leading to the formation of a high density of structural defects like threading dislocations which strongly affect the physical properties of thin films ${ }^{9}$. Large lattice mismatches are also reported to cause small binding force. In this case, the $\mathrm{ZnPc}$ thin film exhibits spontaneous nucleation crystallization ${ }^{10}$. The spontaneous nucleation process could be accounted as a main reason for the shift in the diffraction angle position and for the lower intensity of the XRD patterns in the presence of Au substrates. Thus, in the light of these analyses, the decrease in the intensity of the XRD patterns upon replacement of substrates can be assigned to the decrease in the number of oriented planes along the (002) direction as a result of large lattice mismatches and small binding forces. Earlier 
studied on gold-phthalocyanine interactions indicated that, in general, the different growth modes of phthalocyanine molecules onto metal substrates allow direct control of the $b$ - axis or the one-dimensional chain direction in thin films ${ }^{11}$. The molecule-molecule and molecule-substrate interactions end with variations of the atomic ordering on the substrate. The stronger interactions between gold-phthalocyanine as compared to the phthalocyanine-phthalocyanine interaction, makes the first layer of phthalocyanine grows in a flat layer on the surface and the subsequent layers follow the first layer.

In an attempt to observe the effect of the Au layer on the surface morphology of $\mathrm{ZnPc}$, the scanning electron microscopy technique was employed. Optimizing clear images from the surface of the $\mathrm{ZnPc}$ samples which are grown onto glass was not possible. However, for the $\mathrm{Au} / \mathrm{ZnPc}$ films the scanning electron microscopy revealed the image which is shown in Inset-2 of Figure 1. The inset which represents an enlargement of 10,000 times displayed randomly distributed grains. On average, the grains are irregularly shaped exhibited sizes of $169 \mathrm{~nm}$. While the random distribution of grains means the weak crystallinity (as also suggested by XRD) of the material, this large size of grains indicates the accumulation of many crystallites to form one grain. Generally, the random plane orientations of the accumulated crystallites to form a grain decrease the degree of crystallization.

Figure 2(a) display the absorption coefficient $(\alpha)$ spectra for the $\mathrm{ZnPc}$ thin films which are coated onto glass and transparent $\mathrm{Au}$ substrates. The absorption coefficient is calculated from the measured transmittance $(T)$ and reflectance $(R)$ using the relation, $T \approx\left(1-R_{g l a s s}\right)\left(1-R_{A u}\right)\left(1-R_{A u-Z n P_{c}}\right) \exp (-\alpha d)$. It is evident from Figure 2(a) that the absorption coefficient spectra of the $\mathrm{ZnPc}$ thin films are remarkably influenced by the Au substrate in the incident photon energy range of 3.30-4.10 eV (376-300 nm) and in the infrared range (IR) of light (1.55-1.14 eV, 800-1100 nm) as well. The IR region for the $\mathrm{Au} / \mathrm{ZnPc}$ is shown by green colored circles and enlarged in the inset of Figure 2(b). In this region of light, while the glass/ZnPc show near zero values of absorption coefficient, the spectra of the $\mathrm{Au} / \mathrm{ZnPc}$ increases with decreasing photon energy. Such phenomena are known as free carrier absorption and is ascribed to the weighted contribution of both acoustical phonon scattering and longitudinal optical phonon scattering ${ }^{12}$. Similar to our observation, the enhanced infrared absorption in CdMnTe is mentioned to be caused by the lattice absorption and the free carrier absorption mechanisms. The lattice absorption is believed to arise from the lattice distortion in CdMnTe crystal which is caused by dislocations, inclusions and impurities ${ }^{13}$. The carrier movement which is affected by phonon scattering transfers the energy to lattice when irradiated by IR light leading to the free carrier absorption. The effect of the $\mathrm{Au}$ substrates on the light absorbability of $\mathrm{ZnPc}$ is easily observable from the absorption coefficient ratios $\left(R_{\alpha}\right)$ of the $\mathrm{Au} / \mathrm{ZnPc}$ to glass/ZnPc. $R_{\alpha}$ spectra are shown in Figure 2(b). In general, the light absorbability are larger than one in most of the spectral range. However, it shows large increase and exhibit one local maxima of 4.70 at $2.72 \mathrm{eV}(457 \mathrm{~nm})$ and one absolute maxima of 128.2 at $1.29 \mathrm{eV}(963 \mathrm{~nm})$. This is a relatively high value indicating the better performance of the $\mathrm{Au} / \mathrm{ZnPc}$ over glass/ZnPc films. The large increase in
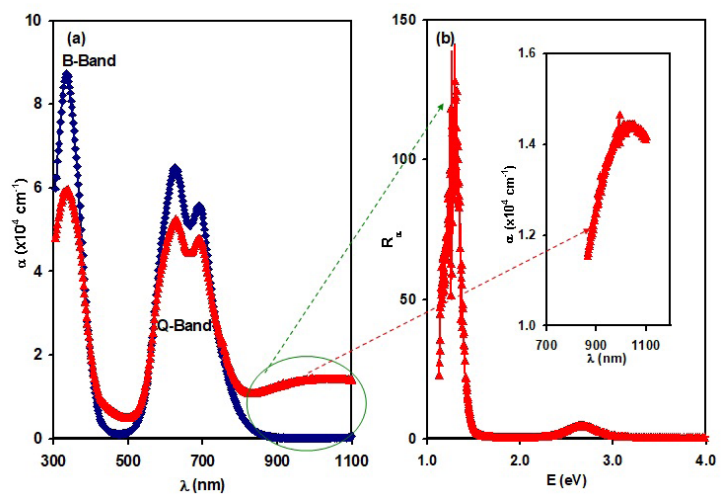

Figure 2. (a) the absorption coefficients and (b) the light absorbability spectra for the glass $/ \mathrm{ZnPc}$ and $\mathrm{Au} / \mathrm{ZnPc}$. The inset of (b) shows the $\alpha-\lambda$ variations of the $\mathrm{Au} / \mathrm{ZnPc}$ in the low absorption region.
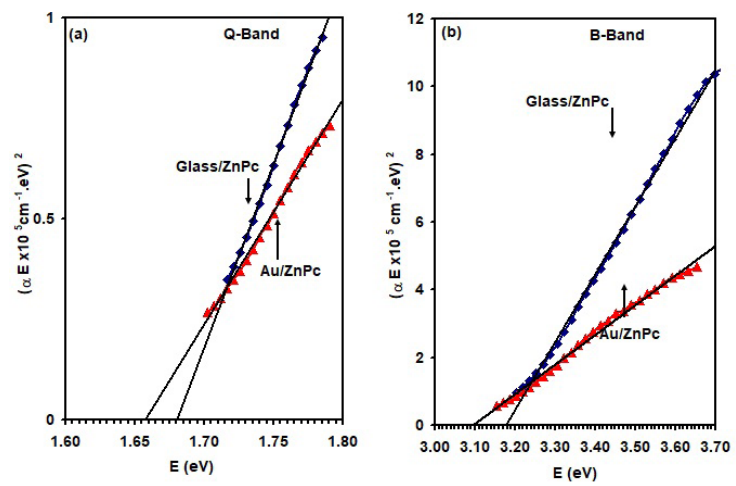

Figure 3. the Tuac's equation fitting for glass/ZnPc and $\mathrm{Au} / \mathrm{ZnPc}$ in the (a) Q band and (b) B band.

the light absorbability make the $\mathrm{Au} / \mathrm{ZnPc}$ films promising materials as IR sensors and attractive for use in solar cells ${ }^{14}$. The enhancement of light absorption upon replacement of glass by $\mathrm{Au}$ is mainly attributed to the free carrier absorption which is motivated by the Au substrates in the IR range.

On the other hand, the employment of Tauc's equation $\left((\alpha E)^{2} \propto\left(E-E_{g}\right)\right)^{15,16}$ to determine the effects of transparent $\mathrm{Au}$ substrates on the optical energy band gaps revealed the straight lines which are shown in Figure 3(a) and 3(b). While the $E$-axis crossings in the $\mathrm{Q}$-band of $\mathrm{ZnPc}$ which is shown in Figure 3(a) display a shift in the value of the energy band gap from 1.680 to $1.663 \mathrm{eV}$, the $E$-axis crossing in the B-band display a shift from 3.175 to $3.095 \mathrm{eV}$ upon replacement of glass by Au substrates. The shrinkage in the energy band gap of $\mathrm{ZnPc}$ which results from Au substrates can be ascribed to the stronger interactions between the $\mathrm{Au}$ and phthalocyanine layers compared to the interactions between phthalocyanine - phthalocyanine layers ${ }^{11}$. It also could be accounted to the quantum size effect, its stated that ${ }^{17}$ when the particle size is in the nanoscale regime a higher energy shift in the conduction band happens owing to the larger surface-to-volume ratio. Because of this ratio majority of the constituent atoms can reside on the particle surface, and induces the efficient transfer of charge carriers to suitable regions on the surface. The narrowing of the 


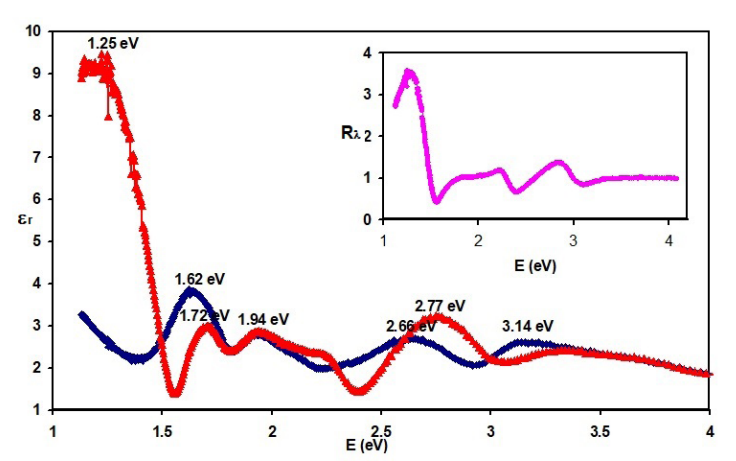

Figure 4. the dielectric constant spectra for the glass/ZnPc and $\mathrm{Au} / \mathrm{ZnPc}$ films. The inset shows the ratio of the dielectric constants.

energy band gaps in both of the Q and B bands could also be assigned to the orbital overlapping ${ }^{15}$ between the $\mathrm{Au}\left(4 f^{14} 5 d^{10} 6 s^{1}\right)$ orbitals and $\mathrm{Zn}\left(4 d^{10} 4 s^{2}\right)$ atoms in $\mathrm{ZnPc}$. The Au metal can add one more free electron to the $\mathrm{ZnPc}$ orbitals as it reaches $6 s^{l}$ states. In general, the optical absorption in the $\mathrm{Q}$ and $\mathrm{B}$ bands in $\mathrm{ZnPc}$ originates from the highest occupied molecular orbitals (HOMO) to the lowest unoccupied molecular orbitals (LUMO) states. The ground state of the HOMO and SHOMO (singlet highest occupied molecular orbital) is due to the $a_{14}(\pi)$ and $a_{24}(\pi)$ orbitals. The first excited LUMO level is $e_{g}\left(\pi^{*}\right)^{18,19}$. The electronic transitions from $a_{14}(\pi)$ to $e_{g}\left(\pi^{*}\right)$ result in Q- and B-band absorptions near 2.0 and $3.65 \mathrm{eV}$. The Q-band splits into two bands centered at 1.75 and $2.0 \mathrm{eV}$ because of the molecular vibration limitations in phthalocyanine microcycles ${ }^{18,19}$. Participation of the $\mathrm{Au}\left(6 s^{I}\right)$ orbitals increases the number of electrons that are available to support these optical transitions which could also account for the changes in the energy band gaps values.

Figure 4 illustrates the real part $\left(\varepsilon_{r}\right)$ of the dielectric spectra for the glass/ZnPc and $\mathrm{Au} / \mathrm{ZnPc}$ thin films. The dielectric spectra are calculated with the help of Fresnel's equations using the measured $T$ and $R$ data ${ }^{15,16}$. The figure displays broaden peaks of $\varepsilon_{r}$ spectra at critical energy values of 3.14, 2.68, 1.94 and $1.62 \mathrm{eV}$ for glass/ZnPc. These peaks appear at $2.77,1.94,1.72$ and $1.25 \mathrm{eV}$ for the $\mathrm{Au} / \mathrm{ZnPc}$ films. While the peaks at $3.14 \mathrm{eV}$ and $2.66 \mathrm{eV}$ are assigned to the transitions in the B bands, the critical energies at 1.94 and $1.62 \mathrm{eV}$ in glass/ZnPc are assigned to the Q-band and SHUMO transitions in $\mathrm{ZnPc}$. The shifted peaks which appeared as a result of Au substrates may be ascribed to the same reasons we mentioned for the attenuations in the energy band gap. The most import point that is worthy of consideration in the dielectric spectra is the large enhancement in the value of the dielectric constant upon coating of $\mathrm{ZnPc}$ onto $\mathrm{Au}$ substrates. The inset of Figure 4 illustrates the ratio $\left(R_{\varepsilon}\right)$ of the dielectric constant of the $\mathrm{Au} / \mathrm{ZnPc}$ to that of glass/ZnPc. It indicated pronounced increase in the values of the ratio with decreasing photon energy in the IR range of light. $R_{\varepsilon}$ reaches maxima of 3.5 at $1.30 \mathrm{eV}$ nominating the $\mathrm{Au} / \mathrm{ZnPc}$ films for use in storing electromagnetic energy in the IR range. The increase in the value of the dielectric constant upon replacement of glass by Au substrates is ascribed to the better dipole polarization. The higher the polarization, the higher the dielectric constant ${ }^{20}$. As we mentioned in the preceding paragraphs of this article, the interfacing of $\mathrm{Au}$ with $\mathrm{ZnPc}$ ends with stronger interactions between the $\mathrm{Au}$ and $\mathrm{ZnPc}$ compared to glass/ ZnPc. Such strong interactions which are assisted by small binding forces lead to the completeness of the bonding and as a result increase in the number of oriented electric dipoles ${ }^{10,11}$.

\section{Conclusions}

In the current study we have shown that interfacing of zinc phthalocyanine with $\mathrm{Au}$ thin layers of thicknesses of $150 \mathrm{~nm}$ could significantly improve the optical properties of $\mathrm{ZnPc}$ and make it more appropriate for optoelectronic technology applications. Both of the light absorbability and dielectric constant are remarkably increased when the films were coated onto Au substrates. It is also observed that the Au caused slight shrinkage in the energy band gaps in both of the B and Q bands of ZnPc. The large values of the dielectric constant at $1.30 \mathrm{eV}$ makes the $\mathrm{Au} / \mathrm{ZnPc}$ films attractive for electromagnetic energy storage.

\section{Acknowledgments}

This work was supported by the Deanship of Scientific Research (DSR), Arab American University, Jenin, Palestine, under grant No. (Cycle 1-2019-2020). The authors, therefore, gratefully acknowledge the DSR technical and financial support.

\section{References}

1. Qin J, Peng H, Ping J, Geng Z. Facile synthesis of dual-functional nanoparticles co-loaded with $\mathrm{ZnPc} / \mathrm{Fe} 3 \mathrm{O} 4$ for PDT and magnetic resonance imaging. Mater Res Bull. 2019;114:90-4. http:// dx.doi.org/10.1016/j.materresbull.2019.02.020.

2. Zheng J, Li X, Qin Y, Zhang S, Sun M, Duan X, et al. Zn phthalocyanine/carbon nitride heterojunction for visible light photoelectrocatalytic conversion of $\mathrm{CO}_{2}$ to methanol. J Catal. 2019;371:214-23. http://dx.doi.org/10.1016/j.jcat.2019.01.022.

3. Ding R, Xu Z, Zheng T, Huang F, Peng Y, Lv W, et al. Realizing high-responsive superlattice organic photodiodes by $\mathrm{C} 60$ and zinc phthalocyanine. J Mater Sci. 2019;54(4):3187-95. http:// dx.doi.org/10.1007/s10853-018-3052-3.

4. Zu Y, He C, Liu D, Chen L. Synthesis of hybrid structures based on metal phthalocyanines/graphene oxide towards nonlinear optical applications. Dyes Pigments. 2020;173:107841. http:// dx.doi.org/10.1016/j.dyepig.2019.107841.

5. Chen C, Cheng Y, Jin J, Dai Q, Song H. CdS/CdSe quantum dots and $\mathrm{ZnPc}$ dye co-sensitized solar cells with Au nanoparticles/ graphene oxide as efficient modified layer. J Colloid Interface Sci. 2016;480:49-56. http://dx.doi.org/10.1016/j.jcis.2016.06.076.

6. Godfrey D, Nirmal D, Arivazhagan L, Kannan RR, Nelson PI, Rajesh S, et al. A novel ZnPc nanorod derived piezoelectric nanogenerator for energy harvesting. Physica E. 2020;118:113931. http://dx.doi.org/10.1016/j.physe.2019.113931.

7. Zi Y, Wang J, Wang S, Li S, Wen Z, Guo H, et al. Effective energy storage from a triboelectric nanogenerator. Nat Commun. 2016;7(1):10987. http://dx.doi.org/10.1038/ncomms10987.

8. Lin Z, Chang J, Xiao J, Zhu H, Xu QH, Zhang C, et al. Interface studies of the planar heterojunction perovskite solar cells. Sol Energy Mater Sol Cells. 2016;157:783-90. http://dx.doi. org/10.1016/j.solmat.2016.07.045.

9. Shimomoto K, Ohta J, Fujii T, Ohba R, Kobayashi A, Oshima $\mathrm{M}$, et al. Epitaxial growth of InN films on lattice-matched EuN 
buffer layers. J Cryst Growth. 2009;311(20):4483-5. http:// dx.doi.org/10.1016/j.jcrysgro.2009.08.020.

10. Lin N, Huo L, Liu H, Fang X, Wu S, Chen X, et al. Preparation and properties of pure crystalline perovskite $\mathrm{CeFeO} 3$ thin films with vanadium doping. J Am Ceram Soc. 2017;100(7):2932-8. http://dx.doi.org/10.1111/jace.14816.

11. Gredig T, Colesniuc CN, Crooker SA, Schuller IK. Substratecontrolled ferromagnetism in iron phthalocyanine films due to one-dimensional iron chains. Phys Rev B Condens Matter Mater Phys. 2012;86(1):014409. http://dx.doi.org/10.1103/ PhysRevB.86.014409.

12. Emelie PY, Phillips J, Buller B, Venkateswaran UD. Free carrier absorption and lattice vibrational modes in bulk $\mathrm{ZnO}$. J Electron Mater. 2006;35(4):525-9. http://dx.doi.org/10.1007/ s11664-006-0094-0.

13. Zhang J, Wang L, Min J, Qin K, Huang J, Tang K, et al. Annealing of indium-doped CdMnTe single crystals under $\mathrm{Cd}$ vapors. J Cryst Growth. 2012;358:12-5. http://dx.doi.org/10.1016/j. jcrysgro.2012.07.048.

14. Dai J, Jiang X, Wang H, Yan D. Organic photovoltaic cells with near infrared absorption spectrum. Appl Phys Lett. 2007;91(25):253503. http://dx.doi.org/10.1063/1.2824836.
15. AlGarni SE, QasrawiAF. Indium slabs induced structural phase transitions and their effects on the electrical and optical properties of stacked layers of the thermally annealed $\mathrm{Cu}_{2} \mathrm{O}$ thin films. Results in Physics. 2020;16(3):102901. http://dx.doi.org/10.1016/j.rinp.2019.102901.

16. Pankove JI. Optical processes in semiconductors. New York: Dover Publications; 1975.

17. Ezhilarasi AA, Vijaya J, Kennedy LJ, Kaviyarasu K. Green mediated NiO nano-rods using Phoenix dactylifera (Dates) extract for biomedical and environmental applications. Mater Chem Phys. 2020;241:122419. http://dx.doi.org/10.1016/j. matchemphys.2019.122419.

18. Senthilarasu S, Sathyamoorthy R, Lalitha S, Subbarayan A, Natarajan K. Thermally evaporated ZnPc thin films: band gap dependence on thickness. Sol Energy Mater Sol Cells. 2004;82(12):179-86. http://dx.doi.org/10.1016/j.solmat.2004.01.016.

19. Von Morzé N, Dittrich T, Calvet W, Lauermann I, Rusu M. Transient and modulated charge separation at $\mathrm{CuInSe} / \mathrm{C}_{60}$ and $\mathrm{CuInSe}_{2} / \mathrm{ZnPc}$ hybrid interfaces. Appl Surf Sci. 2017;396:36674. http://dx.doi.org/10.1016/j.apsusc.2016.10.163.

20. Chand J, Singh M. Electric and dielectric properties of $\mathrm{MgGd}_{0.1} \mathrm{Fe}_{1.9} \mathrm{O}_{4}$ ferrite. J Alloys Compd. 2009;486(1-2):376-9. http://dx.doi.org/10.1016/j.jallcom.2009.06.150. 